\title{
Elizabethkingia Meningoseptica Engodenous Endophthalmitis - a case report
}

\author{
Stephanie Ming Young ${ }^{1 *}$, Gopal Lingam ${ }^{1}$ and Paul Anantharajah Tambyah²
}

\begin{abstract}
Elizabethkingia meningoseptica is a nosocomial non-fermenting gram-negative bacillus that has an increasing prevalence in health care settings, especially in intensive care environments. While it has long been recognized as a rare but serious cause of neonatal meningitis and sepsis, its role as a cause of ocular pathology is not well-known. We report the first case of E. meningoseptica endogenous endophthalmitis caused by bacteraemia by the same organism. In view of its aggressiveness and virulence in the eye, and the high rate of misdiagnosis or missed diagnosis of endogenous endophthalmitis especially given its low incidence, we may wish to consider screening all cases of E. menigoseptica bloodstream infections for endophthalmitis in future, similar to how it has become routine to refer all patients with Klebsiella bacteraemia to ophthalmologists for screening for endophthalmitis in our local hospitals.
\end{abstract}

Keywords: Elizabethkingia meningoseptica, Endogenous endophthalmitis, Infections of the eye

\section{Background}

Elizabethkingia meningoseptica (previously known as Flavobacterium meningosepticum and then Chryseobacterium meningosepticum) is a nosocomial non-fermenting gramnegative bacillus that has intrinsic resistance to many antibiotics commonly used in intensive care settings [1,2]. In addition, it carries many antimicrobial resistance genes, as well as the ability to form biofilms and survive for long periods in a moist environment or in water sources including tap water, making it an important organism in many intensive care environments [3-5]. Unsurprisingly, outbreaks of this bacteria have been reported, including a recent publication reporting an outbreak in our local hospital's cardiothoracic and surgical intensive care units (ICUs) in 2012 (Table 1) [6-10].

Endogenous bacterial endophthalmitis is a rare but serious condition that occurs when bacteria cross the blood-ocular barrier and multiply within the eye. While E. meningoseptica has long been recognized as a rare but serious cause of neonatal meningitis and sepsis, as well as an increasingly important pathogen in healthcare environments, its role as a cause of ocular pathology is not wellknown [11]. So far, there have only been two reported

\footnotetext{
* Correspondence: stephanieyoung83@gmail.com

'Department of Ophthalmology, National University Health System, 1E Kent

Ridge Road, NUHS Tower Block, Singapore 119228, Singapore

Full list of author information is available at the end of the article
}

cases of endophthalmitis related to E. meningoseptica, both of which were post-traumatic and hence, exogenous, in nature $[12,13]$. We report the first case of E. meningoseptica endogenous endophthalmitis caused by bacteraemia by the same organism.

\section{Case presentation}

A 75-year-old Chinese Singaporean lady with multiple comorbidities including Type 2 diabetes mellitus on insulin, hypertension, dyslipidemia, ischaemic heart disease, end-stage renal failure on hemodialysis, degenerative spondylosis and osteoarthritis, was admitted for fever, chills and rigors of one-day duration. There was also discharge of pus over her right femoral dialysis catheter.

She was diagnosed to have disseminated Methicillinsensitive Staphylococcus aureus (MSSA) bacteraemia secondary to infected right femoral non-tunnelled dialysis catheter. Her first nine blood cultures grew MSSA, so did her wound culture. Her femoral line was removed and she was treated in medical intensive care unit (MICU) for her septic shock. She was referred to the infectious diseases (ID) team and she received systemic vancomycin, clindamycin and then cloxacillin over the course of several weeks as culture results became known. The patient subsequently improved clinically with resolution of fever and improvement of haemodynamic parameters. Her inflammatory markers including procalcitonin and white blood 
Table 1 Summary of outbreaks of Elizabethkingia meningoseptica

\begin{tabular}{|c|c|c|c|c|c|}
\hline $\begin{array}{l}\text { Period of } \\
\text { outbreak }\end{array}$ & Type of unit & Population involved & Source of outbreak & Control measures & Outcome \\
\hline $\begin{array}{l}\text { April to October } \\
2002[6]\end{array}$ & $\begin{array}{l}\text { Neonatal intensive } \\
\text { care unit }\end{array}$ & 4 neonates & Not found & $\begin{array}{l}\text { Controlled by reinforcement of usual } \\
\text { measures }\end{array}$ & $\begin{array}{l}\text { No additional colonization/infection } \\
\text { confirmed for }>1 \text { year after last case }\end{array}$ \\
\hline $\begin{array}{l}\text { July } 2006 \text { and } \\
\text { January } 2007 \text { [7] }\end{array}$ & $\begin{array}{l}\text { Neonatal intensive } \\
\text { care unit and pediatric } \\
\text { wards }\end{array}$ & $\begin{array}{l}8 \text { newborns and } \\
5 \text { older children }\end{array}$ & $\begin{array}{l}\text { Hand cultures obtained from a senior } \\
\text { resident; Environmental cultures obtained } \\
\text { from powdered infant formula, an electrical } \\
\text { button, a computer keyboard, phone, a } \\
\text { doorknob, and an Ambu bag }\end{array}$ & $\begin{array}{l}\text { Staff exchange in wards restricted; All } \\
\text { units thoroughly scrubbed using } 2 \\
\text { disinfectants } 3 \text { times a day until outbreak } \\
\text { controlled; Contact precautions. }\end{array}$ & $\begin{array}{l}\text { Nine patients improved on antimicrobial } \\
\text { treatment, and } 4 \text { premature infants died } \\
\text { after infection. }\end{array}$ \\
\hline $\begin{array}{l}\text { December } 2007 \\
\text { through April } \\
2008[8]\end{array}$ & $\begin{array}{l}\text { Long-term acute care } \\
\text { hospital }\end{array}$ & $\begin{array}{l}19 \text { patients with } \\
\text { respiratory failure } \\
\text { on mechanical } \\
\text { ventilation }\end{array}$ & $\begin{array}{l}\text { Environmental sampling: one swab out of } \\
106 \text { surfaces; Patient sampling: E. meningoseptica } \\
\text { isolated from blood, respiratory specimen, } \\
\text { catheter tip }\end{array}$ & $\begin{array}{l}\text { Training on handwashing and disinfection } \\
\text { practices, isolation policies, use of gowns } \\
\text { and gloves, policies implemented } \\
\text { regarding proper disposal of body fluids }\end{array}$ & Eight out of 19 died \\
\hline Fall, 2006 [9] & Orthopaedic wards & $\begin{array}{l}2 \text { patients who had } \\
\text { allograft-associated } \\
\text { surgical site infections }\end{array}$ & $\begin{array}{l}\text { E. meningoseptica was recovered from sink } \\
\text { drains and traps in clean rooms where } \\
\text { tissues were processed }\end{array}$ & $\begin{array}{l}\text { All clean-room sink drains and traps at } \\
\text { processing facility replaced, check valves } \\
\text { in drains installed, routine sanitization of } \\
\text { drains started, }\end{array}$ & $\begin{array}{l}\text { Tissue-processing resumed following } \\
\text { these changes; sterility failure rates } \\
\text { returned to baseline levels with no } \\
\text { identification of E. meningoseptica } \\
\text { or other waterborne gram-negative } \\
\text { bacteria }\end{array}$ \\
\hline $\begin{array}{l}\text { August and } \\
\text { September } \\
2012[10]\end{array}$ & $\begin{array}{l}\text { Intensive care units } \\
\text { (ICUs). }\end{array}$ & 5 patients & $\begin{array}{l}\text { E. meningoseptica was isolated from from } \\
\text { aerators, hand hygiene sinks }\end{array}$ & $\begin{array}{l}\text { Urgent education programme instituted; } \\
\text { Taps were cleaned systematically and } \\
\text { aerators were changed. }\end{array}$ & $\begin{array}{l}\text { Temporary reduction in case numbers } \\
\text { achieved. }\end{array}$ \\
\hline
\end{tabular}


cell count showed decreasing trends. Approximately six weeks after admission, there was documented clearance of MSSA from her blood. The plan by ID was to continue intravenous cloxacillin for a total of six weeks from her last negative blood culture for the presumed endovascular infection although she had a normal two dimensional echocardiograph.

Unfortunately her stay in hospital was delayed as she developed extensive right lower limb deep vein thrombosis, for which she was treated with heparin infusion, inferior vena cava (IVC) filter and subsequently warfarin. Approximately two months into her stay in hospital, she developed an episode of sepsis with desaturation, drop in Glasgow coma scale (GCS) and low grade fever. Urgent neuroimaging revealed no intracranial infarct or hemorrhage. However her subsequent four blood cultures, taken two days apart, all grew Elizabethkingia meningoseptica, which was susceptible to cotrimoxazole, levofloxacin, and minocycline, but resistant to amikacin. She was treated with intravenous antibiotics, comprising courses of cotrimoxazole, cefazolin and meropenem, after consultation with the ID team. Three days after her first positive blood culture for Elizabethkingia meningoseptica, she developed a red and painful left eye with blurring of vision.

A referral to Ophthalmology was promptly made. On examination her right pupil was noted to be sluggish, and left pupil fixed. There was a reverse relative afferent pupillary defect (RAPD). Visual acuity in her right eye was 6/120 (without reading glasses) with no perception of light (NPL) in her left eye. Examination of her left eye showed an injected conjunctiva, hazy cornea with Descemet's membrane (DM) folds, and a deep anterior chamber filled with a hypopyon and fibrin. A glint of an intraocular lens could be seen. There was no view of the fundus but B-scan ultrasonography showed multiple vitreous opacities. The impression was that of left eye endogenous endophthalmitis, for which she underwent an intravitreal tap for vitreous culture, as well as injection of intravitreal vancomycin and amikacin. She was also started on hourly fortified gentamicin and cefazolin eyedrops. In view of the absence of perception of light, as well as her systemic status, vitrectomy was not resorted to. There was also no immediate indication for evisceration.

The patient's vitreous cultures came back positive for Elizabethkingia meningoseptica, which was sensitive to ciprofloxacin, levofloxacin, cotrimoxazole, and minocycline, but resistant to ceftazidine, gentamicin and amikacin. In consideration of the sensitivity results, the intravitreal antibiotics were switched to ciprofloxacin (100 micrograms $/ 0.05 \mathrm{ml})$. The injection was repeated five times before it was felt that the infection was under reasonable control. The fibrin clot in her anterior chamber progressively resolved and the inflammatory material in the vitreous cavity became organised. The eye was quiet with no pain. While vision was not expected to recover, the need for evisceration was successfully averted.

Potential environmental source links were investigated. Workflows for ward staff were reviewed. Environmental screening was performed by swab cultures of surfaces and equipment within patient rooms, taps and aerators, water sampling and sampling of chlorhexidine solution. While no clear source of the bacteria was identified, it was presumably from aerators and hand hygiene sinks, as was found in a previous investigation of the same bacteria in the hospital [10].

\section{Discussion}

Elizabethkingia menigoseptica has reduced susceptibility to a broad range of antimicrobials, including beta lactams, aminoglycosides and chloramphenicol. It is an opportunistic pathogen being most often associated with meningitis and septicemia in a pediatric (especially neonatal) population. It has also been identified as a cause of healthcare-associated pneumonia, sepsis and meningitis in adults, particularly in immunocompromised patients, those with indwelling central venous catheters and those with long hospital stays. Mortality in patients with E. meningoseptica bacteraemia or meningitis may be high $(>50 \%)$ depending on the population studied $[7,14,15]$.

To date, there have only been two case reports on E. meningoseptica-related endophthalmitis, both exogenous in nature, in contrast to our patient who had an endogenous cause $[12,13]$. One was a case of deliberate ocular penetration with an unsterile sewing needle in a patient with depressive illness, while the other was a case of penetrating eye injury caused by a truck tyre explosion resulting in a self-sealing full thickness corneal wound with two metallic posterior segment foreign bodies [13]. While the above two cases differ from ours in the nature of the infection, there are similarities in all cases: the infection in the eye occurred acutely, progressed very quickly from one to three days, behaved virulently and produced an intense fibrinous reaction in the anterior and posterior segments of the eye. E. meningoseptica cultured from the vitreous, like those from other parts of the body, was found to be resistant to many antibiotics. Ciprofloxacin was one antibiotic to which it was sensitive to in all three cases, and hence may be considered as first-line therapy (systemic and intravitreal) in future cases of E. meningoseptica related endophthalmitis.

There have been no previous reports of E. meningoseptica causing endogenous endophthalmitis, which occurs when organisms reach the eye via the bloodstream, and enter the internal ocular spaces by crossing the blood-ocular barrier. Endogenous bacterial endophthalmitis is treated seriously because they are serious infections with poor 
visual outcomes [16]. The outcomes worsen with several factors: delay in diagnosis, use of inappropriate antibiotics, diffuse infection of the vitreous and retina or panophthalmitis, poor vision at presentation, infection with virulent organisms and gram negative infection [16]. Gram negative endophthalmitis is more common in East Asian hospitals, with the most common bacteria being Klebsiella spp, Escherichia coli, Pseudomonas aeruginosa, Neisseria meningitides and Serratia marscescens. In fact because of its virulence and prevalence, it has become routine, in our local hospitals, to refer all patients with Klebsiella bacteraemia to ophthalmologists for screening for endophthalmitis.

Elizabethkingia menigoseptica, like Klebsiella spp, has shown to behave in a virulent manner in the eye. With its increasing prevalence in health care settings, especially in intensive care environments due to its propensity to form biofilms, it is of utmost importance for physicians to have a high vigilance for this opportunistic pathogen. While its presence in the blood may not necessarily require an automatic referral for eye screening, they should consider an early eye referral if the patient has any signs (conjunctival injection or chemosis, periocular redness and swelling, hazy cornea, hypopyon in anterior chamber, reduced or absent red reflex) or symptoms (floaters, blurring of vision, eye pain, tearing, redness) of an eye infection. However, in view of the aggressiveness and virulence of this bacteria, and the likelihood of misdiagnosis or missed diagnosis of endogenous endophthalmitis especially given its low incidence, we may want to consider screening all cases of E. menigoseptica bloodstream infections for endophthalmitis in future.

This case also brings up the issue of potential contamination of taps and aerators within ICUs as important sources of E. meningoseptica infection as may have been in this case $[6,8,10]$. E. meningoseptica is an opportunistic pathogen that is well adapted to the intensive care environment due to its intrinsic resistance to antimicrobials commonly used in the ICU setting and its propensity to form biofilms. The latter are difficult to eradicate, particularly where the organism has established on an indwelling device such as a vascular line or endotracheal tube.

Previous outbreaks have shown a multitude of potential sources of the bacteria, including sink drains, taps, aerators, catheters, blood and respiratory specimens, hand cultures, infant formula, electrical buttons, a computer keyboards, phone, doorknobs, Ambu bags etc. [6-10]. Beyond the potential contribution of E. meningoseptica to the deterioration of the severely ill adult patient, transmission of E. meningoseptica from environmental reservoirs to neonates is a known infection outbreak scenario. Infection control personnel in acute care hospitals must be aware of E. meningoseptica in chronically ill patients, especially those on mechanical ventilation in ICUs. Attention should also be paid to non-adherence to existing policies regarding disposal of patient secretions and cleaning of re-usable patient care items, time pressures and distance between patient rooms and ward utility rooms notwithstanding.

Design of wards particularly within the critical care setting must consider physical and personnel requirements to facilitate safe delivery of care, and staff workflows must be optimized to facilitate patient safety and avoid inadvertently putting patients at risk with lapses in safety procedures [10].

\section{Conclusion}

In conclusion, the incidence of endogenous endophthalmitis by $E$. meningoseptica and other bacteria is reportedly low, but clinicians must not fail to appreciate the overlap between ocular and systemic disease. Prompt diagnosis and treatment is essential if useful vision is to be preserved and therefore ophthalmologists, physicians, and microbiologists need to have a high level of awareness of this disease to reduce harm to our patients.

\section{Consent}

Written informed consent was obtained from the patient for publication of this Case report and any accompanying images. A copy of the written consent is available for review by the Editor-in-Chief of this journal.

\section{Competing interests}

The authors declare that they have no competing interests.

\section{Authors' contributions}

SYM was in charge of case review and preparation of the manuscript. GL provided clinic expert opinion regarding the case and helped to draft the manuscript. PAT conceived of the study, participated in its coordination and helped in the editing of the manuscript. All authors read and approved the final manuscript.

\section{Author details}

${ }^{1}$ Department of Ophthalmology, National University Health System, 1E Kent Ridge Road, NUHS Tower Block, Singapore 119228, Singapore. ${ }^{2}$ Department of Medicine, National University Health System, 1E Kent Ridge Road, NUHS Tower Block, Singapore 119228, Singapore.

Received: 1 August 2014 Accepted: 3 November 2014 Published: 26 November 2014

\section{References}

1. Bloch KC, Nadarajah R, Jacobs R: Chryseobacterium meningosepticum. Medicine 1997, 76:30-41.

2. Kim KK, Kim MK, Lim JH, Park HY, Lee ST: Transfer of Chryseobacterium meningosepticum and Chryseobacterium miricola to Elizabethkingia gen. nov. as Elizabethkingia meningoseptica comb. nov. and Elizabethkingia miricola comb. nov. Int J Syst Evol Microbiol 2005, 55:1287-1293.

3. Lin PY, Chen HL, Huang CT, Su LH, Chiu CH: Biofilm production, use of intravascular indwelling catheters and inappropriate antimicrobial therapy as predictors of fatality in Chryseobacterium meningosepticum bacteraemia. Int J Antimicrob Agents 2010, 36:436-440.

4. Jiang $X$, Wang $D$, Wang $Y$, Yan H, Shi L, Zhou L: Occurrence of antimicrobial resistance genes sul and dfrA12 in hospital environmental 
isolates of Elizabethkingia meningoseptica. World J Microbiol Biotechnol 2012, 28:3097-3102.

5. Yum JH, Lee EY, Hur SH, Jeong SH, Lee H, Yong D, Chong Y, Lee EW, Nordmann P, Lee K: Genetic diversity of chromosomal metallo-b-lactamase genes in clinical isolates of Elizabethkingia meningoseptica from Korea. J Microbiol 2010, 48:358-364.

6. Maraki S, Scoulica E, Manoura A, Papageorgiou N, Giannakopoulou C, Galanakis E: Chryseobacterium meningosepticum colonization outbreak in a neonatal intensive care unit. Eur J Clin Microbiol Infect Dis 2009, 28:1415-1419.

7. Ceyhan M, Yildirim I, Tekeli A, Yurdakok M, Us E, Altun B, Kutluk T, Cengiz AB, Gurbuz V, Barin C, Bagdat A, Cetinkaya D, Gur D, Tuncel O: A Chryseobacterium meningosepticum outbreak observed in 3 clusters involving both neonatal and non-neonatal pediatric patients. Am J Infect Control 2008, 36:453-457.

8. Weaver KN, Jones RC, Albright R, Thomas Y, Zambrano CH, Costello M, Havel J, Price J, Gerber SI: Acute emergence of Elizabethkingia meningoseptica infection among mechanically ventilated patients in a long-term acute care facility. Infect Control Hosp Epidemiol 2010, 31:54-58.

9. Cartwright EJ, Prabhu RM, Zinderman CE, Schobert WE, Jensen B, Noble-Wang J, Church K, Welsh C, Kuehnert M, Burke TL, Srinivasan A, Food and Drug Administration Tissue Safety Team Investigators: Transmission of Elizabethkingia meningoseptica (formerly Chryseobacterium meningosepticum) to tissue-allograft recipients - a report of two cases. J Bone Joint Surg 2010, 92:1501-1506

10. Balm MN, Salmon S, Jureen R, Teo C, Mahdi R, Seetoh T, Teo JT, Lin RT, Fisher DA: Bad design, bad practices, bad bugs: frustrations in controlling an outbreak of Elizabethkingia meningoseptica in intensive care units. J Hosp Infect 2013, 85:134-140.

11. King EO: Studies on a group of previously unclassified bacteria associated with meningitis in infants. Am J Clin Pathol 1959, 31:241-247.

12. Connell PP, Wickremasinghe S, Devi U, Waters MJ, Allen PJ: Self-induced Elizabethkingia meningoseptica endophthalmitis: a case report. J Med Case Reports 2011, 5:303,

13. Essex RW, Charles PGP, Allen PJ: Three cases of post-traumatic endophthalmitis caused by unusual bacteria. Clin Experiment Ophthalmol 2004, 32:435-439.

14. Hsu MS, Liao CH, Huang YT, Liu CY, Yang CJ, Kao KL, Hsueh PR: Clinical features, antimicrobial susceptibilities, and outcomes of Elizabethkingia meningoseptica (Chryseobacterium meningosepticum) bacteremia at a medical center in Taiwan, 1999-2006. Eur J Clin Microbiol Infect Dis 2011, 30:1271-1278

15. Lin YT, Chiu CH, Chan YJ, Lin ML, Yu KW, Wang FD, Liu CY: Clinical and microbiological analysis of Elizabethkingia meningoseptica bacteremia in adult patients in Taiwan. Scand J Infect Dis 2009, 41:628-634.

16. Jackson TL, Eykyn SJ, Graham EM, Stanford MR: Endogenous bacterial endophthalmitis: a 17-year prospective series and review of 267 reported cases. Surv Opthalmolog 2003, 48:403-423.

doi:10.1186/2047-2994-3-35

Cite this article as: Young et al: Elizabethkingia Meningoseptica

Engodenous Endophthalmitis - a case report. Antimicrobial Resistance and Infection Control 2014 3:35.

\section{Submit your next manuscript to BioMed Central and take full advantage of:}

- Convenient online submission

- Thorough peer review

- No space constraints or color figure charges

- Immediate publication on acceptance

- Inclusion in PubMed, CAS, Scopus and Google Scholar

- Research which is freely available for redistribution 